\title{
DFT Calculation on 76 Polychlorophenazines: Their Thermodynamic Function and Implication of Cl Substituted Position
}

\author{
Hong-Xia Yu, ${ }^{1}$ Hui Liu, ${ }^{2}$ Zun-Yao Wang, ${ }^{2}$ and Lian-Sheng Wang1 \\ ${ }^{1}$ Department of Environment, Nanjing University, Nanjing 214007, Jiangsu, China \\ ${ }^{2}$ School of Biological and Chemical Engineering, Jiaxing University, Jiaxing 314001, Zhejiang, China
}

Correspondence should be addressed to Zun-Yao Wang, wangzun315cn@163.com

Received 18 April 2008; Revised 1 August 2008; Accepted 10 September 2008

Recommended by Z. Zhang

Thermodynamic functions, including enthalpy $\left(H^{\theta}\right)$ and entropy $\left(S^{\theta}\right)$ for 76 polychlorophenazines (PCPZs) in the gas state at $298.15 \mathrm{~K}$ and $101.325 \mathrm{kPa}$, have been calculated using the B3LYP/6-31G* level with Gaussian 03 program, and considered on solvation affects. Total free energy in water $\left(G_{w}\right)$ was calculated with the same program. Based on these data, the isodesmic reactions were designed to calculate the standard formation heat $\left(\Delta_{f} H^{\theta}\right)$ and standard free energy of formation in water $\left(\Delta_{f} G_{w}^{\theta}\right)$. The dependences of these thermodynamic parameters on the numbers and positions of chlorine substitution $\left(N_{\mathrm{PCS}}\right)$ were discussed. It is suggested that $S^{\theta}, \Delta_{f} H^{\theta}$, and $\Delta_{f} G_{w}^{\theta}$ of PCPZs varied greatly with $N_{\mathrm{PCS}}$. Moreover, the values of molar heat capacity at constant pressure $\left(C_{p, m}\right)$ from 200 to $1800 \mathrm{~K}$ for PCPZ congeners were calculated using a statistical thermodynamics calculation program based on Gaussian output files, and the temperature-dependence relation of $C_{p, m}$ was obtained using the least-squares method. In addition, according to the relative magnitude of their $\Delta_{f} G_{w}^{\theta}$, the relative stability order of PCPZ congeners was theoretically proposed.

Copyright (C) 2008 Hong-Xia Yu et al. This is an open access article distributed under the Creative Commons Attribution License, which permits unrestricted use, distribution, and reproduction in any medium, provided the original work is properly cited.

\section{Introduction}

Phenazine (PZ) shows properties of a wide range in significant applications $[1,2]$. Natural and synthetic phenazines have attracted considerable attention because of their interesting biological activities [3], that is, antibiotic and anticancer agents $[4,5]$. Halosubstituted phenazines are useful as herbicides [6]. Because of there increasing dosage of chlorophenzines in recent years, their concentrations in the environment have also increased. Using the in vitro bioassay for dioxin-like activity showed that TBPZ has an $\mathrm{ED}_{50}$ of $10^{-7} \mathrm{M}$ [7]. It can draw the conclusion that polychlorophenzines also have dioxin-like activity. For studying their generation, degradation, and environmental risk, it is important to know the thermodynamic properties of PCPZs. In addition, solvation has huge effect on organic reactivity/stability, and these studies were reported previously. For example, Warshel [8] studied computer modeling of chemical reactions in enzymes and solutions; Bren et al.
[9] studied the reaction between chloroethylene oxide and guanine; Kranjc and Mavri [10] reported the calculations of the activation free energy for a chemical reaction between ethylene oxide and guanine; Florián and Warshel [11] calculated chemical processes in aqueous solution using a new parameterization of the Langevin dipole (LD) model.

We have studied the thermodynamic properties for PCDFs, PCPTs, PBDF, PBNs and PCDTs [12-16]. The purpose of the study was to calculate the thermodynamic properties for 76 PCPZs. And considered on solvation affects, total free energy in water $\left(G_{w}\right)$ was calculated with the same program. Then, the relationship between these parameters and the numbers and positions of chlorine substitution $\left(N_{\mathrm{PCS}}\right)$ were studied. By designing isodesmic reactions, the standard enthalpies of formation $\left(\Delta_{f} H^{\theta}\right)$ and the standard Gibbs energies of formation in water $\left(\Delta_{f} G_{w}^{\theta}\right)$ for all PCPZs were also obtained. On the basis of the relative magnitude of their $\Delta_{f} G_{w}^{\theta}$, the relative stability order of PCPZ congeners was theoretically proposed and then compared with that of 


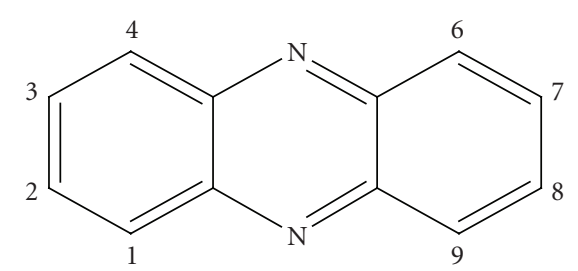

FIGURE 1: The numbering of the C-atoms.

polychlorinated dibenzo-p-dioxin (PCDD) isomers. Finally, the $C_{p, m}$ values of PCPZ congeners were calculated using statistical thermodynamics calculation program at 200$1800 \mathrm{~K}$.

\section{Computational Methods}

With Gaussian 03 program [17], geometry optimizations were performed at the $\mathrm{B} 3 \mathrm{LYP} / 6-31 \mathrm{G}^{*}$ level at the state of $298.15 \mathrm{~K}$ and $101.325 \mathrm{kPa}$. And considered on solvation affects, total free energy in water $\left(G_{w}\right)$ was calculated with the same program. In terms of the numbers and different positions of constituted chlorine atoms, there are 76 possible structural patterns of PCPZs. Standard enthalpies $\left(H^{\theta}\right)$, total free energy in water $(G)$, and standard entropy $\left(S^{\theta}\right)$ for 76 PCPZs were obtained from the Gaussian output files. As for the notation in this paper, PCPZ congeners with one to eight chlorine atoms are represented by MCPZ, DCPZ, TriCPZ, TCPZ, Penta-CPZ, Hexa-CPZ, Hepta-CPZ, and Octa$\mathrm{CPZ}$, respectively. Prefix numbers represent the positions (see Figure 1) of chlorine substitution (e.g., 2,3,7,8-TCPZ or simply 2,3,7,8-).

Lee et al. [18] used the isodesmic reaction to calculate the $\Delta_{f} H$ and $\Delta_{f} G$ of PCDDs and obtained results consistent to experimental results. So it seems reasonable to expect that estimates of the thermodynamic properties of PCPZs, from DFT calculations based on isodesmic reactions, will be similarly accurate.

In this study, reaction 1 was designed for calculating $\Delta_{f} H^{\theta}$ and $\Delta_{f} G^{\theta}$ :

$$
\mathrm{PZ}+n \text { chlorobenzene }=\mathrm{PCPZ}+n \text { benzene }
$$

From the reaction above, $\Delta_{f} H^{\theta}$ and $\Delta_{f} G^{\theta}$ of PCPZs can be obtained, as follows:

$$
\begin{aligned}
\Delta_{f} H_{\mathrm{PCPZ}}^{\theta}= & H_{\mathrm{PCPZ}}^{\theta}+n H_{\text {benzene }}^{\theta}-n H_{\text {chlorobenzene }}^{\theta}-H_{\mathrm{PZ}}^{\theta} \\
& -n \Delta_{f} H_{\text {benzene }}^{\theta}+n \Delta_{f} H_{\text {chlorobenzene }}^{\theta}+\Delta_{f} H_{\mathrm{PZ}}^{\theta}, \\
\Delta_{f} G_{\mathrm{PCPZ}}^{\theta}= & G_{\mathrm{PCPZ}}^{\theta}+n G_{\text {benzene }}^{\theta}-n G_{\text {chlorobenzene }}^{\theta}-G_{\mathrm{PZ}}^{\theta} \\
& -n \Delta_{f} G_{\text {benzene }}^{\theta}+n \Delta_{f} G_{\text {chlorobenzene }}^{\theta}+\Delta_{f} G_{\mathrm{PZ}}^{\theta} .
\end{aligned}
$$

Equation (4) was used to calculate $\Delta_{f} G^{\theta}(\mathrm{PZ})$ :

$$
\mathrm{N}_{2}+12 \mathrm{C}_{(\text {Graphite })}+4 \mathrm{H}_{2}=\mathrm{C}_{12} \mathrm{H}_{8} \mathrm{~N}_{2} \text {. }
$$

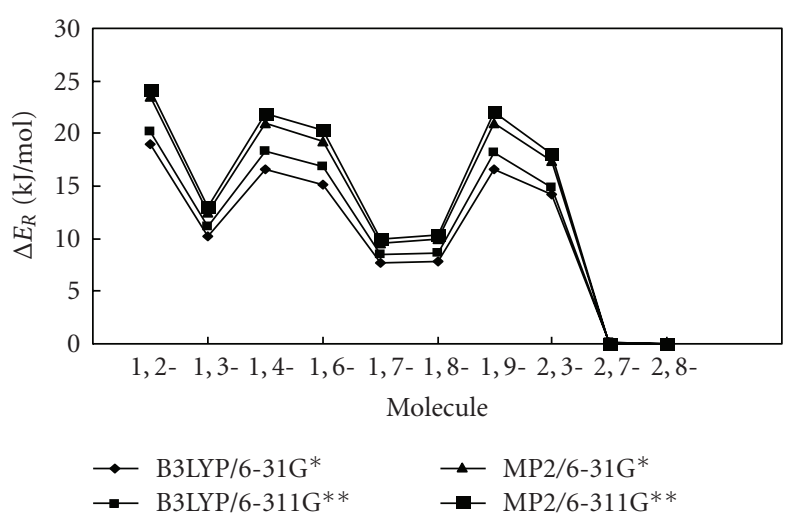

FIgure 2: The change tendency of $\Delta E$ for Di-PZs at different levels.

Then

$$
\begin{gathered}
\Delta_{\mathrm{r}} S^{\theta}=S_{(\mathrm{PZ})}^{\theta}-S_{\left(\mathrm{N}_{2}\right)}^{\theta}-12 S_{(\mathrm{C})}^{\theta}-4 S_{\left(\mathrm{H}_{2}\right)}^{\theta}, \\
\Delta_{\mathrm{r}} H^{\theta}=\Delta_{f} H_{(\mathrm{PZ})}^{\theta}-\Delta_{f} H_{\left(\mathrm{N}_{2}\right)}^{\theta}-12 \Delta_{f} H_{(\mathrm{C})}^{\theta}-4 \Delta_{f} H_{\left(\mathrm{H}_{2}\right)}^{\theta}=\Delta_{f} H_{(\mathrm{PZ})}^{\theta}, \\
\Delta_{f} G_{(\mathrm{PZ})}^{\theta}=\Delta_{\mathrm{r}} H_{(\mathrm{PZ})}^{\theta}-\mathrm{T} \Delta_{\mathrm{r}} S_{(\mathrm{PZ})}^{\theta} .
\end{gathered}
$$

The experimental and calculated values of $\Delta_{f} H^{\theta}, \Delta_{f} G^{\theta}$, $H^{\theta}, G^{\theta}$, and $S^{\theta}$ for benzene, chlorobenzene, phenazine, graphite, nitrogen, and hydrogen are listed in Table 1.

\section{Results and Discussions}

In this work, the general structure of PZ is shown in Figure 1, and the numbering of the $\mathrm{C}$-atoms in the phenyl rings is indicated. The numbers of chlorine atoms at positions 1(4, $6,9)$ and $2(3,7,8)$ are defined as $N_{\alpha}$ and $N_{\beta}$, the pair numbers of chlorine at positions 1,9 or 4,6 are defined as $N_{1,9}$; the pair numbers of chlorine at ortho-, meta-, and para-positions are defined as $N_{o}, N_{m}$, and $N_{p}$, respectively. Moreover, the parameters mentioned above are defined as a general designation $N_{\text {PCS. }}$.

\subsection{Comparison of the Calculated Results at Different Levels}

The $S^{\theta}$ of PZ, Mono-PZs, and Di-PZs were also calculated at the B3LYP/6-311G** level, and listed in Table 2. Seen from Table 2, the differences of $S^{\theta}$ between the calculated results at two different levels were small, in which the maximum discrepancy of $S^{\theta}$ is only $0.18 \mathrm{~J} \cdot(\mathrm{mol} \cdot \mathrm{K})^{-1}$. Moreover, the values of $E$ for ten Di-PZs were calculated at levels of B3LYP and MP2. Defined the most smallest value of $E$ at each level as zero, the $\Delta E_{\mathrm{R}}$ was obtained by the values of others minus the smallest value, and also listed in Table 2 . The change tendency of $\Delta E_{\mathrm{R}}$ for Di-PZs was shown in Figure 2.

In addition, compared $\Delta E$ as shown in Table 2 and Figure 2, it was found that $\Delta E$ of 1,2-PZ calculated using four methods are all maximum and that of 2,8-PZ are all minimum. And the discrepancy of $\Delta E$ between the two compounds, by MP2/6-311G**, MP2/6-31G*, B3LYP/6$311 \mathrm{G}^{* *}$, and $\mathrm{B} 3 \mathrm{LYP} / 6-31 \mathrm{G}^{*}$, is $24.19 \mathrm{~kJ} \cdot \mathrm{mol}^{-1}, 23.44$ 
TABle 1: Thermodynamic data used for calculating $\Delta_{f} H^{\theta}$ and $\Delta_{f} G^{\theta}$ of PCPZs.

\begin{tabular}{|c|c|c|c|c|c|c|}
\hline Number & Formula or name & $\Delta_{f} H^{\theta} /\left(\mathrm{kJ} \cdot \mathrm{mol}^{-1}\right)$ & $\Delta_{f} G^{\theta} /\left(\mathrm{kJ} \cdot \mathrm{mol}^{-1}\right)$ & $H^{\theta} /($ Hartree $)$ & $G^{\theta} /($ Hartree $)$ & $S^{\theta} /\left(\mathrm{J} \cdot \mathrm{mol}^{-1} \cdot \mathrm{K}^{-1}\right)$ \\
\hline 1 & Benzene $(\mathrm{PhH})$ & $82.9^{\mathrm{a}}$ & $129.66^{\mathrm{a}}$ & -232.14258 & -232.17302 & - \\
\hline 2 & Chlorobenzene(CB) & $51.8^{\mathrm{a}}$ & $99.07^{\mathrm{a}}$ & -691.74731 & -691.78288 & - \\
\hline 3 & Phenazine(PZ) & $237.0^{\mathrm{a}}$ & - & -571.425835 & -571.470458 & 93.916 \\
\hline 4 & Graphite $(\mathrm{C})$ & 0 & - & - & - & $5.74^{\mathrm{a}}$ \\
\hline 5 & $\operatorname{Nitrogen}\left(\mathrm{N}_{2}\right)$ & 0 & - & - & - & $45.77^{\mathrm{a}}$ \\
\hline 6 & Hydrogen $\left(\mathrm{H}_{2}\right)$ & 0 & - & - & - & $130.57^{\mathrm{a}}$ \\
\hline
\end{tabular}

${ }^{\mathrm{a}}$ Data from [19] and other data from B3LYP/6-31G* calculations.

TABLE 2: Comparison of $S^{\theta}$ and $\Delta E_{\mathrm{R}}$ calculated at different levels.

\begin{tabular}{|c|c|c|c|c|c|c|c|}
\hline \multirow{2}{*}{ Molecule } & \multicolumn{3}{|c|}{$S^{\theta} / \mathrm{J} \cdot(\mathrm{mol} \cdot \mathrm{K})^{-1}$} & \multicolumn{4}{|c|}{$\Delta E_{\mathrm{R}} / \mathrm{kJ} \cdot \mathrm{mol}^{-1}$} \\
\hline & B3LYP/6-31G* & B3LYP/6-311G** & Diff & B3LYP/6-31G* & B3LYP/6-311G** & MP2/6-31G* & $\mathrm{MP} 2 / 6-311 \mathrm{G}^{* *}$ \\
\hline $\mathrm{PZ}$ & 93.92 & 94.04 & 0.12 & - & - & - & - \\
\hline $1-$ & 100.97 & 101.07 & 0.10 & - & - & - & - \\
\hline $2-$ & 101.21 & 101.33 & 0.12 & - & - & - & - \\
\hline $1,2-$ & 107.85 & 107.97 & 0.12 & 19.00 & 20.12 & 23.44 & 24.19 \\
\hline $1,3-$ & 108.22 & 108.40 & 0.18 & 10.17 & 11.11 & 12.51 & 13.00 \\
\hline $1,4-$ & 108.09 & 108.26 & 0.17 & 16.61 & 18.30 & 20.91 & 21.88 \\
\hline $1,6-$ & 108.11 & 108.28 & 0.17 & 15.10 & 16.79 & 19.29 & 20.29 \\
\hline $1,7-$ & 108.26 & 108.36 & 0.11 & 7.67 & 8.44 & 9.50 & 9.98 \\
\hline $1,8-$ & 108.23 & 108.39 & 0.16 & 7.87 & 8.69 & 9.92 & 10.41 \\
\hline $1,9-$ & 108.08 & 108.25 & 0.17 & 16.55 & 18.25 & 21.01 & 21.97 \\
\hline $2,3-$ & 107.98 & 108.16 & 0.18 & 14.17 & 14.86 & 17.38 & 18.06 \\
\hline $2,7-$ & 108.39 & 108.52 & 0.13 & 0.10 & 0.10 & 0.02 & 0.05 \\
\hline $2,8-$ & 108.35 & 108.52 & 0.17 & 0.00 & 0.00 & 0.00 & 0.00 \\
\hline
\end{tabular}

$\mathrm{kJ} \cdot \mathrm{mol}^{-1}, 20.12 \mathrm{~kJ} \cdot \mathrm{mol}^{-1}$, and $19.00 \mathrm{~kJ} \cdot \mathrm{mol}^{-1}$, respectively. The values of $\Delta E$ calculated using four methods are different, but the order of the relative magnitude and the change tendency of $\Delta E$ are accordant. So the relative stability order of PCPZ congeners proposed at the B3LYP/6-31G* level was feasible theoretically.

\subsection{Relation of the Numbers and Positions of Chlorine Substitute $\left(N_{\mathrm{PCS}}\right)$ to $S^{\theta}$}

Up to date, there hasn't been experimental thermodynamic data of PCPZs reported systematically. In this work, $S^{\theta}$ can be directly obtained from the output files of Gaussian programs and presented in Table 3.

Using multiple linear regression method of the SPSS 12.0 for windows program, the relation between $N_{\text {PCS }}$ and $S^{\theta}$ can be seen in (6). The squared regression coefficient $R^{2}$ is 1000 and standard deviation SD is 0.05 . From the equation, the number of chlorine substitute has obvious effect on entropy, but the spatial effect of chlorine on the parameter $S^{\theta}$ is minor and the decrease effect is ortho $\gg$ meta $>$ para. $S^{\theta}$ value is increased about $7 \mathrm{~J} \cdot \mathrm{mol}^{-1} \cdot \mathrm{K}^{-1}$ when increasing each chlorine atom to PCPZs:

$$
\begin{aligned}
S^{\theta}= & 93.93+7.11 N_{\alpha}+7.22 N_{\beta}-0.01 N_{1,9}-0.38 N_{o} \\
& -0.05 N_{m}+0.00 N_{p}, \quad R^{2}=1.000 \mathrm{SD}=0.05
\end{aligned}
$$

\subsection{Calculated Results of $\Delta_{f} H^{\theta}$ and $\Delta_{f} G_{w}^{\theta}$ Value and Relative Stability of Isomer Groups}

With the isodesmic reactions, $\Delta_{f} H^{\theta}$ and $\Delta_{f} G_{w}^{\theta}$ of PCPZs were obtained and presented in Table 3. Using multiple linear regression method, the correlation expressions of $\Delta_{f} H^{\theta}$ and $\Delta_{f} G_{w}^{\theta}$ to $N_{\text {PCS }}$ were summarized and presented in (7) and (8), respectively. The correlations of (7) is very well due to the corresponding larger $r^{2}$ as well as (8), both of which represent the influence of the number of chlorine on the value of $\Delta_{f} H^{\theta}$ and $\Delta_{f} G^{\theta}$ clearly:

$$
\begin{aligned}
\Delta_{f} H^{\theta}= & 235.08-19.89 N_{\alpha}-26.47 N_{\beta}+1.57 N_{1,9}+12.91 N_{o} \\
& +3.12 N_{m}+1.97 N_{p}, \quad R^{2}=0.997 \mathrm{SD}=1.16 \\
\Delta_{f} G_{w}^{\theta}= & 392.87+22.31 N_{\alpha}+14.24 N_{\beta}+12.94 N_{o} \\
& +5.03 N_{m}, \quad R^{2}=0.997 \mathrm{SD}=2.83 .
\end{aligned}
$$

It is suggested that $\Delta_{f} H^{\theta}$ and $\Delta_{f} G_{w}^{\theta}$ of PCPZs varied greatly with the positions of chlorine substitution, with an order of decrement for these parameters being position $\beta>$ position $\alpha$. It was also found that $\Delta_{f} H^{\theta}$ and $\Delta_{f} G_{w}^{\theta}$ increase with two chlorines at the same aromatic ring, and the increase effect order is ortho $\gg$ meta $>$ para.

Of the PCPZ compounds in each isomer group, the isomers with lower relative standard Gibbs energy of formation are relatively more stable, whereas those with the 
TABLE 3: Thermodynamic parameters by B3LYP/6-31G* for PCPZs.

\begin{tabular}{|c|c|c|c|c|c|c|c|c|c|c|c|c|c|c|}
\hline \multirow{2}{*}{ Molecular } & \multirow{2}{*}{$\begin{array}{c}S^{\theta} \\
\mathrm{J} \cdot(\mathrm{mol} \cdot \mathrm{K})^{-1}\end{array}$} & \multirow{2}{*}{$\begin{array}{c}\Delta_{f} H^{\theta} \\
\mathrm{kJ} \cdot \mathrm{mol}^{-1}\end{array}$} & \multirow{2}{*}{$\begin{array}{c}\Delta_{f} G_{w}^{\theta} \\
\mathrm{kJ} \cdot \mathrm{mol}^{-1}\end{array}$} & \multirow{2}{*}{$\begin{array}{c}\Delta_{f} G_{w, \mathrm{R}}^{\theta} \\
\mathrm{kJ} \cdot \mathrm{mol}^{-1}\end{array}$} & \multicolumn{4}{|c|}{$C_{p, m}, \mathrm{~J} \cdot(\mathrm{mol} \cdot \mathrm{K})^{-1}$} & \multirow{2}{*}{$N_{\alpha}$} & \multirow{2}{*}{$N_{\beta}$} & \multirow{2}{*}{$N_{o}$} & \multirow{2}{*}{$N_{m}$} & \multirow{2}{*}{$N_{p}$} & \multirow{2}{*}{$N_{1,9}$} \\
\hline & & & & & Constant & $10^{3} \mathrm{~T}$ & $10^{4} T^{-1}$ & $10^{6} T^{-2}$ & & & & & & \\
\hline $\mathrm{PZ}$ & 93.9 & $237.0^{\mathrm{a}}$ & 398.9 & & 575.69 & 2.15 & 1.67 & 1.54 & 0 & 0 & 0 & 0 & 0 & 0 \\
\hline $1-$ & 101.0 & 216.3 & 416.30 & 5.60 & 582.01 & 1.24 & 1.62 & 1.46 & 1 & 0 & 0 & 0 & 0 & 0 \\
\hline $2-$ & 101.2 & 208.7 & 410.71 & 0.00 & 581.67 & 1.18 & 1.61 & 1.46 & 0 & 1 & 0 & 0 & 0 & 0 \\
\hline $1,2-$ & 107.9 & 200.4 & 440.95 & 18.52 & 588.57 & 4.71 & 1.56 & 1.39 & 1 & 1 & 1 & 0 & 0 & 0 \\
\hline $1,3-$ & 108.2 & 191.5 & 434.08 & 11.65 & 588.22 & 4.63 & 1.56 & 1.39 & 1 & 1 & 0 & 1 & 0 & 0 \\
\hline $1,4-$ & 108.1 & 198.1 & 437.34 & 14.92 & 588.44 & 4.65 & 1.56 & 1.39 & 2 & 0 & 0 & 0 & 1 & 0 \\
\hline $1,6-$ & 108.1 & 196.6 & 435.79 & 13.37 & 588.40 & 4.66 & 1.56 & 1.39 & 2 & 0 & 0 & 0 & 0 & 0 \\
\hline $1,7-$ & 108.3 & 189.0 & 429.11 & 6.68 & 588.03 & 4.58 & 1.55 & 1.38 & 1 & 1 & 0 & 0 & 0 & 0 \\
\hline $1,8-$ & 108.2 & 189.2 & 429.03 & 6.60 & 588.06 & 4.59 & 1.55 & 1.38 & 1 & 1 & 0 & 0 & 0 & 0 \\
\hline 1,9- & 108.1 & 198.0 & 438.74 & 16.32 & 588.45 & 4.67 & 1.56 & 1.39 & 2 & 0 & 0 & 0 & 0 & 1 \\
\hline $2,3-$ & 108.0 & 195.4 & 438.28 & 15.85 & 588.24 & 4.64 & 1.56 & 1.38 & 0 & 2 & 1 & 0 & 0 & 0 \\
\hline $2,7-$ & 108.4 & 181.2 & 422.90 & 0.48 & 587.70 & 4.51 & 1.55 & 1.38 & 0 & 2 & 0 & 0 & 0 & 0 \\
\hline $2,8-$ & 108.3 & 181.1 & 422.43 & 0.00 & 587.69 & 4.51 & 1.55 & 1.38 & 0 & 2 & 0 & 0 & 0 & 0 \\
\hline $1,2,3-$ & 114.7 & 190.7 & 474.61 & 26.97 & 595.38 & 8.27 & 1.51 & 1.32 & 1 & 2 & 2 & 1 & 0 & 0 \\
\hline $1,2,4-$ & 115.0 & 184.9 & 467.91 & 20.27 & 595.19 & 8.17 & 1.51 & 1.32 & 2 & 1 & 1 & 1 & 1 & 0 \\
\hline $1,2,6-$ & 115.0 & 181.3 & 460.39 & 12.75 & 594.97 & 8.13 & 1.50 & 1.32 & 2 & 1 & 1 & 0 & 0 & 0 \\
\hline $1,2,7-$ & 115.1 & 173.6 & 453.76 & 6.12 & 594.59 & 8.04 & 1.50 & 1.31 & 1 & 2 & 1 & 0 & 0 & 0 \\
\hline $1,2,8-$ & 115.1 & 173.7 & 454.56 & 6.92 & 594.61 & 8.06 & 1.50 & 1.31 & 1 & 2 & 1 & 0 & 0 & 0 \\
\hline $1,2,9-$ & 115.0 & 182.6 & 464.38 & 16.73 & 595.03 & 8.15 & 1.50 & 1.32 & 2 & 1 & 1 & 0 & 0 & 1 \\
\hline $1,3,6-$ & 115.3 & 172.6 & 454.84 & 7.20 & 594.67 & 8.06 & 1.50 & 1.31 & 2 & 1 & 0 & 1 & 0 & 0 \\
\hline $1,3,7-$ & 115.5 & 164.8 & 447.84 & 0.19 & 594.33 & 8.00 & 1.50 & 1.31 & 1 & 2 & 0 & 1 & 0 & 0 \\
\hline $1,3,8-$ & 115.5 & 164.9 & 447.64 & 0.00 & 594.31 & 7.99 & 1.50 & 1.31 & 1 & 2 & 0 & 1 & 0 & 0 \\
\hline $1,3,9-$ & 115.3 & 173.6 & 457.51 & 9.86 & 594.70 & 8.08 & 1.50 & 1.31 & 2 & 1 & 0 & 1 & 0 & 1 \\
\hline $1,4,6-$ & 115.2 & 180.4 & 461.27 & 13.63 & 594.95 & 8.11 & 1.50 & 1.32 & 3 & 0 & 0 & 0 & 1 & 1 \\
\hline $1,4,7-$ & 115.4 & 171.5 & 450.72 & 3.07 & 594.53 & 8.01 & 1.50 & 1.31 & 2 & 1 & 0 & 0 & 1 & 0 \\
\hline $2,3,6-$ & 115.1 & 176.5 & 458.91 & 11.26 & 594.69 & 8.09 & 1.50 & 1.31 & 1 & 2 & 1 & 0 & 0 & 0 \\
\hline $2,3,7-$ & 115.2 & 168.6 & 451.44 & 3.80 & 594.35 & 8.01 & 1.49 & 1.30 & 0 & 3 & 1 & 0 & 0 & 0 \\
\hline $1,2,3,4-$ & 121.4 & 187.7 & 511.64 & 37.59 & 602.62 & 11.92 & 1.46 & 1.26 & 2 & 2 & 3 & 2 & 1 & 0 \\
\hline $1,2,3,6-$ & 121.7 & 172.1 & 493.95 & 19.90 & 601.87 & 11.72 & 1.45 & 1.25 & 2 & 2 & 2 & 1 & 0 & 0 \\
\hline $1,2,3,7-$ & 122.0 & 164.3 & 489.41 & 15.36 & 601.48 & 11.64 & 1.44 & 1.24 & 1 & 3 & 2 & 1 & 0 & 0 \\
\hline $1,2,3,8-$ & 121.9 & 164.4 & 488.71 & 14.66 & 601.49 & 11.63 & 1.44 & 1.24 & 1 & 3 & 2 & 1 & 0 & 0 \\
\hline $1,2,3,9-$ & 121.8 & 173.3 & 497.72 & 23.66 & 601.91 & 11.74 & 1.45 & 1.25 & 2 & 2 & 2 & 1 & 0 & 1 \\
\hline $1,2,4,6-$ & 122.1 & 167.6 & 492.05 & 17.99 & 601.69 & 11.62 & 1.45 & 1.25 & 3 & 1 & 1 & 1 & 1 & 1 \\
\hline $1,2,4,7-$ & 122.2 & 158.9 & 481.24 & 7.19 & 601.31 & 11.54 & 1.45 & 1.24 & 2 & 2 & 1 & 1 & 1 & 0 \\
\hline $1,2,4,8-$ & 122.1 & 158.9 & 481.76 & 7.71 & 601.33 & 11.55 & 1.45 & 1.24 & 2 & 2 & 1 & 1 & 1 & 0 \\
\hline $1,2,4,9-$ & 122.1 & 167.7 & 491.84 & 17.78 & 601.74 & 11.64 & 1.45 & 1.25 & 3 & 1 & 1 & 1 & 1 & 1 \\
\hline $1,2,6,7-$ & 121.9 & 166.3 & 485.61 & 11.56 & 601.55 & 11.60 & 1.45 & 1.24 & 2 & 2 & 2 & 0 & 0 & 0 \\
\hline $1,2,6,8-$ & 122.2 & 157.6 & 480.07 & 6.01 & 601.29 & 11.55 & 1.44 & 1.24 & 2 & 2 & 1 & 1 & 0 & 0 \\
\hline $1,2,6,9-$ & 122.1 & 165.5 & 486.32 & 12.26 & 601.55 & 11.58 & 1.45 & 1.25 & 3 & 1 & 1 & 0 & 1 & 1 \\
\hline $1,2,7,8-$ & 122.0 & 161.5 & 484.21 & 10.15 & 601.29 & 11.56 & 1.44 & 1.24 & 1 & 3 & 2 & 0 & 0 & 0 \\
\hline $1,2,7,9-$ & 122.2 & 158.8 & 483.56 & 9.51 & 601.29 & 11.55 & 1.44 & 1.24 & 2 & 2 & 1 & 1 & 0 & 1 \\
\hline $1,2,8,9-$ & 121.8 & 167.6 & 490.32 & 16.26 & 601.61 & 11.62 & 1.45 & 1.24 & 2 & 2 & 2 & 0 & 0 & 1 \\
\hline $1,3,6,8-$ & 122.4 & 149.3 & 474.06 & 0.00 & 600.99 & 11.48 & 1.44 & 1.24 & 2 & 2 & 0 & 2 & 0 & 0 \\
\hline $1,3,6,9-$ & 122.3 & 157.0 & 480.35 & 6.29 & 601.24 & 11.51 & 1.45 & 1.24 & 3 & 1 & 0 & 1 & 1 & 1 \\
\hline $1,3,7,8-$ & 122.2 & 152.8 & 477.27 & 3.22 & 600.97 & 11.49 & 1.44 & 1.23 & 1 & 3 & 1 & 1 & 0 & 0 \\
\hline $1,3,7,9-$ & 122.4 & 150.0 & 476.43 & 2.37 & 600.99 & 11.49 & 1.44 & 1.24 & 2 & 2 & 0 & 2 & 0 & 1 \\
\hline $1,4,6,9-$ & 122.3 & 164.7 & 487.84 & 13.79 & 601.51 & 11.55 & 1.45 & 1.25 & 4 & 0 & 0 & 0 & 2 & 2 \\
\hline $1,4,7,8-$ & 122.1 & 159.6 & 480.73 & 6.68 & 601.22 & 11.52 & 1.44 & 1.24 & 2 & 2 & 1 & 0 & 1 & 0 \\
\hline $2,3,7,8-$ & 122.0 & 156.3 & 480.52 & 6.47 & 600.99 & 11.50 & 1.44 & 1.23 & 0 & 4 & 2 & 0 & 0 & 0 \\
\hline $1,2,3,4,6-$ & 128.5 & 170.6 & 536.64 & 25.09 & 609.15 & 15.38 & 1.40 & 1.18 & 3 & 2 & 3 & 2 & 1 & 1 \\
\hline
\end{tabular}


TABle 3: Continued.

\begin{tabular}{|c|c|c|c|c|c|c|c|c|c|c|c|c|c|c|}
\hline \multirow{2}{*}{ Molecular } & \multirow{2}{*}{$\begin{array}{c}S^{\theta} \\
\mathrm{J} \cdot(\mathrm{mol} \cdot \mathrm{K})^{-1}\end{array}$} & \multirow{2}{*}{$\begin{array}{c}\Delta_{f} H^{\theta} \\
\mathrm{kJ} \cdot \mathrm{mol}^{-1}\end{array}$} & \multirow{2}{*}{$\begin{array}{c}\Delta_{f} G_{w}^{\theta} \\
\mathrm{kJ} \cdot \mathrm{mol}^{-1}\end{array}$} & \multirow{2}{*}{$\begin{array}{c}\Delta_{f} G_{w, \mathrm{R}}^{\theta} \\
\mathrm{kJ} \cdot \mathrm{mol}^{-1}\end{array}$} & \multicolumn{4}{|c|}{$C_{p, m}, \mathrm{~J} \cdot(\mathrm{mol} \cdot \mathrm{K})^{-1}$} & \multirow{2}{*}{$N_{\alpha}$} & \multirow{2}{*}{$N_{\beta}$} & \multirow{2}{*}{$N_{o}$} & \multirow{2}{*}{$N_{m}$} & \multirow{2}{*}{$N_{p}$} & \multirow{2}{*}{$N_{1,9}$} \\
\hline & & & & & Constant & $10^{3} \mathrm{~T}$ & $10^{4} T^{-1}$ & $10^{6} T^{-2}$ & & & & & & \\
\hline $1,2,3,4,7-$ & 128.6 & 162.0 & 526.50 & 14.95 & 608.78 & 15.31 & 1.40 & 1.18 & 2 & 3 & 3 & 2 & 1 & 0 \\
\hline $1,2,3,6,7-$ & 128.6 & 157.4 & 519.92 & 8.37 & 608.48 & 15.20 & 1.39 & 1.17 & 2 & 3 & 3 & 1 & 0 & 0 \\
\hline $1,2,3,6,8-$ & 129.0 & 149.2 & 515.79 & 4.24 & 608.20 & 15.15 & 1.39 & 1.17 & 2 & 3 & 2 & 2 & 0 & 0 \\
\hline $1,2,3,6,9-$ & 128.9 & 156.8 & 520.97 & 9.42 & 608.45 & 15.17 & 1.39 & 1.17 & 3 & 2 & 2 & 1 & 1 & 1 \\
\hline $1,2,3,7,8-$ & 128.7 & 152.6 & 518.51 & 6.96 & 608.19 & 15.15 & 1.39 & 1.17 & 1 & 4 & 3 & 1 & 0 & 0 \\
\hline $1,2,3,7,9-$ & 128.9 & 150.0 & 517.98 & 6.44 & 608.20 & 15.15 & 1.39 & 1.17 & 2 & 3 & 2 & 2 & 0 & 1 \\
\hline $1,2,3,8,9-$ & 128.7 & 158.6 & 523.53 & 11.99 & 608.50 & 15.21 & 1.39 & 1.17 & 2 & 3 & 3 & 1 & 0 & 1 \\
\hline $1,2,4,6,7-$ & 128.9 & 153.1 & 517.96 & 6.42 & 608.31 & 15.10 & 1.39 & 1.18 & 3 & 2 & 2 & 1 & 1 & 1 \\
\hline $1,2,4,6,8-$ & 129.3 & 144.6 & 512.53 & 0.98 & 608.04 & 15.06 & 1.39 & 1.17 & 3 & 2 & 1 & 2 & 1 & 1 \\
\hline $1,2,4,6,9-$ & 129.2 & 152.4 & 518.64 & 7.10 & 608.29 & 15.08 & 1.40 & 1.18 & 4 & 1 & 1 & 1 & 2 & 2 \\
\hline $1,2,4,7,8-$ & 129.0 & 147.3 & 512.80 & 1.25 & 608.02 & 15.06 & 1.39 & 1.17 & 2 & 3 & 2 & 1 & 1 & 0 \\
\hline $1,2,4,7,9-$ & 129.3 & 144.7 & 511.55 & 0.00 & 608.03 & 15.05 & 1.39 & 1.17 & 3 & 2 & 1 & 2 & 1 & 1 \\
\hline $1,2,4,8,9-$ & 129.0 & 153.1 & 518.28 & 6.74 & 608.34 & 15.12 & 1.39 & 1.18 & 3 & 2 & 2 & 1 & 1 & 1 \\
\hline $1,2,3,4,6,7-$ & 135.4 & 156.3 & 563.76 & 23.06 & 615.78 & 18.87 & 1.35 & 1.11 & 3 & 3 & 4 & 2 & 1 & 1 \\
\hline $1,2,3,4,6,8-$ & 135.6 & 148.0 & 557.70 & 17.00 & 615.51 & 18.82 & 1.34 & 1.11 & 3 & 3 & 3 & 3 & 1 & 1 \\
\hline $1,2,3,4,6,9-$ & 135.5 & 155.7 & 564.27 & 23.56 & 615.77 & 18.84 & 1.35 & 1.11 & 4 & 2 & 3 & 2 & 2 & 2 \\
\hline $1,2,3,4,7,8-$ & 135.3 & 150.6 & 557.35 & 16.65 & 615.49 & 18.82 & 1.34 & 1.10 & 2 & 4 & 4 & 2 & 1 & 0 \\
\hline $1,2,3,6,7,8-$ & 135.5 & 149.1 & 557.52 & 16.82 & 615.39 & 18.80 & 1.34 & 1.10 & 2 & 4 & 4 & 2 & 0 & 0 \\
\hline $1,2,3,6,7,9-$ & 135.7 & 144.6 & 540.70 & 0.00 & 615.24 & 18.71 & 1.34 & 1.10 & 3 & 3 & 3 & 2 & 1 & 1 \\
\hline $1,2,3,6,8,9-$ & 135.6 & 144.8 & 553.46 & 12.76 & 615.24 & 18.70 & 1.34 & 1.11 & 3 & 3 & 3 & 2 & 1 & 1 \\
\hline $1,2,3,7,8,9-$ & 135.3 & 150.0 & 558.88 & 18.18 & 615.41 & 18.80 & 1.34 & 1.10 & 2 & 4 & 4 & 2 & 0 & 1 \\
\hline $1,2,4,6,7,9-$ & 136.0 & 140.4 & 550.28 & 9.58 & 615.12 & 18.62 & 1.34 & 1.11 & 4 & 2 & 2 & 2 & 2 & 2 \\
\hline $1,2,4,6,8,9-$ & 135.9 & 140.4 & 549.89 & 9.19 & 615.10 & 18.61 & 1.34 & 1.11 & 4 & 2 & 2 & 2 & 2 & 2 \\
\hline $1,2,3,4,6,7,8-$ & 142.1 & 148.2 & 599.58 & 4.08 & 622.73 & 22.48 & 1.29 & 1.04 & 3 & 4 & 5 & 3 & 1 & 1 \\
\hline $1,2,3,4,6,7,9-$ & 142.4 & 143.8 & 595.49 & 0.00 & 622.59 & 22.39 & 1.29 & 1.04 & 4 & 3 & 4 & 3 & 2 & 2 \\
\hline $1,2,3,4,6,7,8,9-$ & 148.7 & 147.4 & 641.63 & & 630.04 & 26.15 & 1.24 & 0.98 & 4 & 4 & 6 & 4 & 2 & 2 \\
\hline
\end{tabular}

${ }^{\mathrm{a}}$ Data from [19].

higher relative standard Gibbs energy of formation are more unstable. Supposed the lowest $\Delta_{f} G_{w}^{\theta}$ of isomers with the same numbers of substituent to be zero, the relative standard Gibbs energies of formation $\left(\Delta_{f} G_{w, \mathrm{R}}^{\theta}\right)$ were obtained, by $\Delta_{f} G_{w}^{\theta}$ of other isomers minus the lowest $\Delta_{f} G_{w}^{\theta}$ of isomers with the same substituent numbers. Then, according to the magnitude of $\Delta_{f} G_{w, R}^{\theta}$, the theoretic relative stability orders of the isomers were proposed, and the most stable isomer and the most unstable one are listed in Table 4. As can be observed from Table 4, the most unstable isomers in MCPTs, DCPTs, Tri-CPTs, TCPTs, Penta-CPTs, HexaCPTs, and Hepta-CPTs are all those with chlorines being attached at the same aromatic ring and close to each other. On the contrary, the most stable isomers are all those with bromines replaced at two aromatic rings as possible, so that the bromines can be apart from each other.

We have calculated the gas phase thermodynamic functions of polychlorinated dibenzo-p-dioxins (PCDDs) via DFT method and designed isodesmic reactions [20]. The relative contents of isomers were found to correlate with the values of free energies, that is, the isomer with lower free energy has higher relative content. So it can be concluded that the formation ratio of isomer with lower $\Delta_{f} G_{w, \mathrm{R}}^{\theta}$ is
TABle 4: Most stable and unstable isomers in different isomer groups for PCPZs.

\begin{tabular}{lcc}
\hline Compounds & The most stable isomer & The most unstable isomer \\
\hline MCPT & $2-$ & $1-$ \\
DCPT & $2,8-; 2,7-$ & $1,2-$ \\
Tri-CPT & $1,3,8-; 1,3,7-$ & $1,2,3-$ \\
TCPT & $1,3,6,8-$ & $1,2,3,4-$ \\
Penta-CPT & $1,2,4,7,9-$ & $1,2,3,4,6-$ \\
Hexa-CPT & $1,2,3,6,7,9-$ & $1,2,3,4,6,7-$ \\
Hepta-CPT & $1,2,3,4,6,7,9-$ & $1,2,3,4,6,7,8-$ \\
\hline
\end{tabular}

higher, while the formation ratio of isomer with higher $\Delta_{f} G_{w, \mathrm{R}}^{\theta}$ is lower, which is similar to that of PCDDs.

\subsection{The Temperature Dependence of Molar Heat Capacity of PCPZs at Constant Pressure}

The values of molar heat capacity at constant pressure $\left(C_{p, m}\right)$ for PCPZs congeners haven't been reported. So, the values of $C_{p, m}$ were calculated using statistical thermodynamics 
calculation program at 200 to $1800 \mathrm{~K}$ based on Gaussian output files.

Based on the calculated values of $C_{p, m}$ of PCPZs at different temperature $(T)$, the relations between $C_{p, m}$ and temperature were obtained using the least-square method. Regression coefficients for $10^{3} \mathrm{~T}, 10^{4} \mathrm{~T}^{-1}, 10^{6} \mathrm{~T}^{-2}$, and constant are listed in Table 3. From Table 3, the following conclusion can be drawn. (1) The $C_{p, m}$ values of PCPZs are in direct ratio to temperature $T, T^{-1}$, and $T^{-2}$. (2) All PCPZ congeners have very good relationships between $C_{p, m}$ and temperature $\left(T, T^{-1}\right.$, and $\left.T^{-2}\right)$, and the correlation coefficients $\left(r^{2}\right)$ are all very close or equal to 1.0. These indicated that a good correlation between $C_{p, m}$ values and $T$.

\section{Conclusions}

76 PCPZs were fully optimized at B3LYP/6-31G* level, and thus their $H^{\theta}, S^{\theta}$, and $G_{w}$ were consequently obtained. In addition, the standard formation heat and standard formation free energy of each PCPZ molecule were calculated by isodesmic reactions. The result showed that all these thermodynamic parameters have close relationship with the numbers and positions of chlorine substituents $\left(N_{\mathrm{PCS}}\right)$. So, the enthalpies and Gibbs free energies of formation for 76 PCPZ congeners should be valuable in further thermodynamic modeling studies. According to the relative magnitude of their $\Delta_{f} G_{w}^{\theta}$, the order of relative stability of PCPZ congeners was theoretically proposed. Moreover, it is found that there is a very good relationship between $C_{p, m}$ and temperature for the PCPZ congeners. In a word, this work about thermodynamic properties is useful and significative for studying the generation, degradation, and potential environmental risk of PCPZs.

\section{Acknowledgment}

This work was financially supported by the National Natural Science Foundation of China (20737001).

\section{References}

[1] K. J. McCullough, "Pyrazines and related ring structures," in Rodd's Chemistry of Carbon Compounds, M. F. Ansell, Ed., vol. 4, p. 354, Elsevier, Amsterdam, The Netherlands, 1989.

[2] R. Bolton, "Phenazine, oxazine, thiazine and sulfur dyes," in Rodd's Chemistry of Carbon Compounds, M. Sainsbury, Ed., vol. 4, pp. 162-172, Elsevier, Amsterdam, The Netherlands, 2000.

[3] V. F. de Andrade-Neto, M. O. F. Goulart, J. F. da Silva Filho, et al., "Antimalarial activity of phenazines from lapachol, $\beta$ lapachone and its derivatives against Plasmodium falciparum in vitro and Plasmodium berghei in vivo," Bioorganic \& Medicinal Chemistry Letters, vol. 14, no. 5, pp. 1145-1149, 2004.

[4] W. Wang, P. Préville, N. Morin, S. Mounir, W. Cai, and M. A. Siddiqui, "Hepatitis C viral IRES inhibition by phenazine and phenazine-like molecules," Bioorganic \& Medicinal Chemistry Letters, vol. 10, no. 11, pp. 1151-1154, 2000.

[5] J. A. Spicer, S. A. Gamage, G. W. Rewcastle, et al., "Bis(phenazine-1-carboxamides): structure-activity relation- ships for a new class of dual topoisomerase I/II directed anticancer drugs," Journal of Medicinal Chemistry, vol. 43, no. 7, pp. 1350-1358, 2000.

[6] B. Cross, C. L. Dunn, D. H. Payne, and J. D. Tipton, "Synthesis and pesticidal activity of phenazines. II. Alkyl, alkoxy, alkylthio and alkylsulphonyl phenazines," Journal of the Science of Food and Agriculture, vol. 20, no. 6, pp. 340-344, 1969.

[7] A. M. Alsabbagh, J. F. Gierthy, R. S. Narang, K. M. Aldous, and P. O'Keefe, "Formation of bromodioxin analogs from closed tube pyrolysis of 2,4,6-tribromoaniline," Chemosphere, vol. 17, no. 12, pp. 2391-2396, 1988.

[8] A. Warshel, Computer Modelling of Chemical Reactions in Enzymes and Solutions, John Wiley \& Sons, New York, NY, USA, 1991.

[9] U. Bren, M. Zupan, F. P. Guengerich, and J. Mavri, “Chemical reactivity as a tool to study carcinogenicity: reaction between chloroethylene oxide and guanine," Journal of Organic Chemistry, vol. 71, no. 11, pp. 4078-4084, 2006.

[10] A. Kranjc and J. Mavri, "Guanine alkylation by ethylene oxide: calculation of chemical reactivity," Journal of Physical Chemistry A, vol. 110, no. 17, pp. 5740-5744, 2006.

[11] J. Florián and A. Warshel, "Langevin dipoles model for ab initio calculations of chemical processes in solution: parametrization and application to hydration free energies of neutral and ionic solutes and conformational analysis in aqueous solution," Journal of Physical Chemistry B, vol. 101, no. 28, pp. 5583-5595, 1997.

[12] Z. Y. Wang, Z. C. Zhai, and L. S. Wang, "Prediction of gas phase thermodynamic properties of polychlorinated dibenzofurans by DFT," Journal of Molecular Structure: THEOCHEM, vol. 725, no. 1-3, pp. 55-62, 2005.

[13] X. Y. Wei, H. Liu, Z. Y. Wang, and J. J. Zhu, "Computational note on thermodynamic function of Polychlorinated Phenoxathiins (PCPTs)," Journal of Molecular Structure: THEOCHEM, vol. 857, no. 1-3, pp. 126-127, 2008.

[14] J. Yu, X. C. Zhang, Z. Y. Wang, and X.-L. Zeng, "Study on the thermodynamic properties and stability of a series of polybrominated dibenzo-furans by density functional theory," Acta Chimica Sinica, vol. 64, no. 19, pp. 1961-1968, 2006.

[15] L. X. Yuan, J. Yu, Z. Y. Wang, H. X. Liu, and X. H. $\mathrm{Ju}$, "Thermodynamic property and relative stability of 76 polybrominated naphthalenes by density functional theory," Journal of Chemical and Engineering Data, vol. 51, no. 6, pp. 2032-2037, 2006.

[16] S. D. Chen, H. X. Liu, and Z. Y. Wang, "Study of structural and thermodynamic properties for polychlorinated dibenzothiophenes(PCDTs) by density functional theory(DFT)," Journal of Chemical \& Engineering Data, vol. 52, no. 4, pp. 1195-1202, 2007.

[17] M. J. Frisch, G. W. Trucks, H. B. Schlegel, et al., "“'Gaussian 03,” Revision A. 1," Gaussian, Inc., Pittsburgh Pa, USA, 2003.

[18] J. E. Lee, W. Choi, and B. J. Mhin, "DFT calculation on the thermodynamic properties of polychlorinated dibenzop-dioxins: intramolecular $\mathrm{Cl}-\mathrm{Cl}$ repulsion effects and their thermochemical implications," Journal of Physical Chemistry A, vol. 107, no. 15, pp. 2693-2699, 2003.

[19] Y. B. Yao, T. Xie, and Y. M. Gao, Handbook of Physics and Chemistry, Shanghai Science and Technology Press, Shanghai, China, 1985.

[20] Z. Y. Wang, Z. C. Zhai, L. S. Wang, J. L. Chen, O. Kikuchi, and T. Watanabe, "Prediction of gas phase thermodynamic function of polychlorinated dibenzo- $p$-dioxins using DFT," Journal of Molecular Structure: THEOCHEM, vol. 672, no. 1-3, pp. 97-104, 2004. 

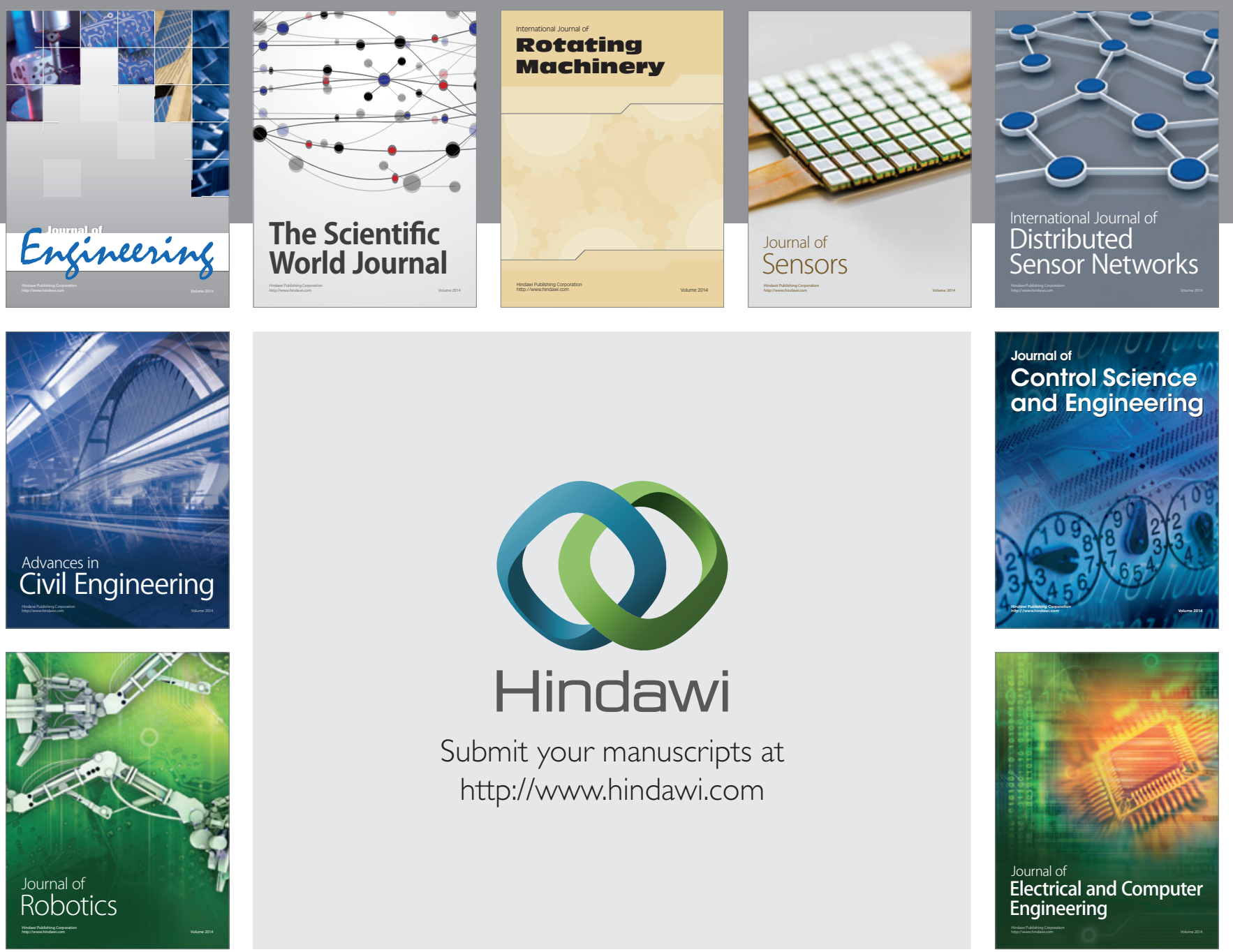

Submit your manuscripts at

http://www.hindawi.com
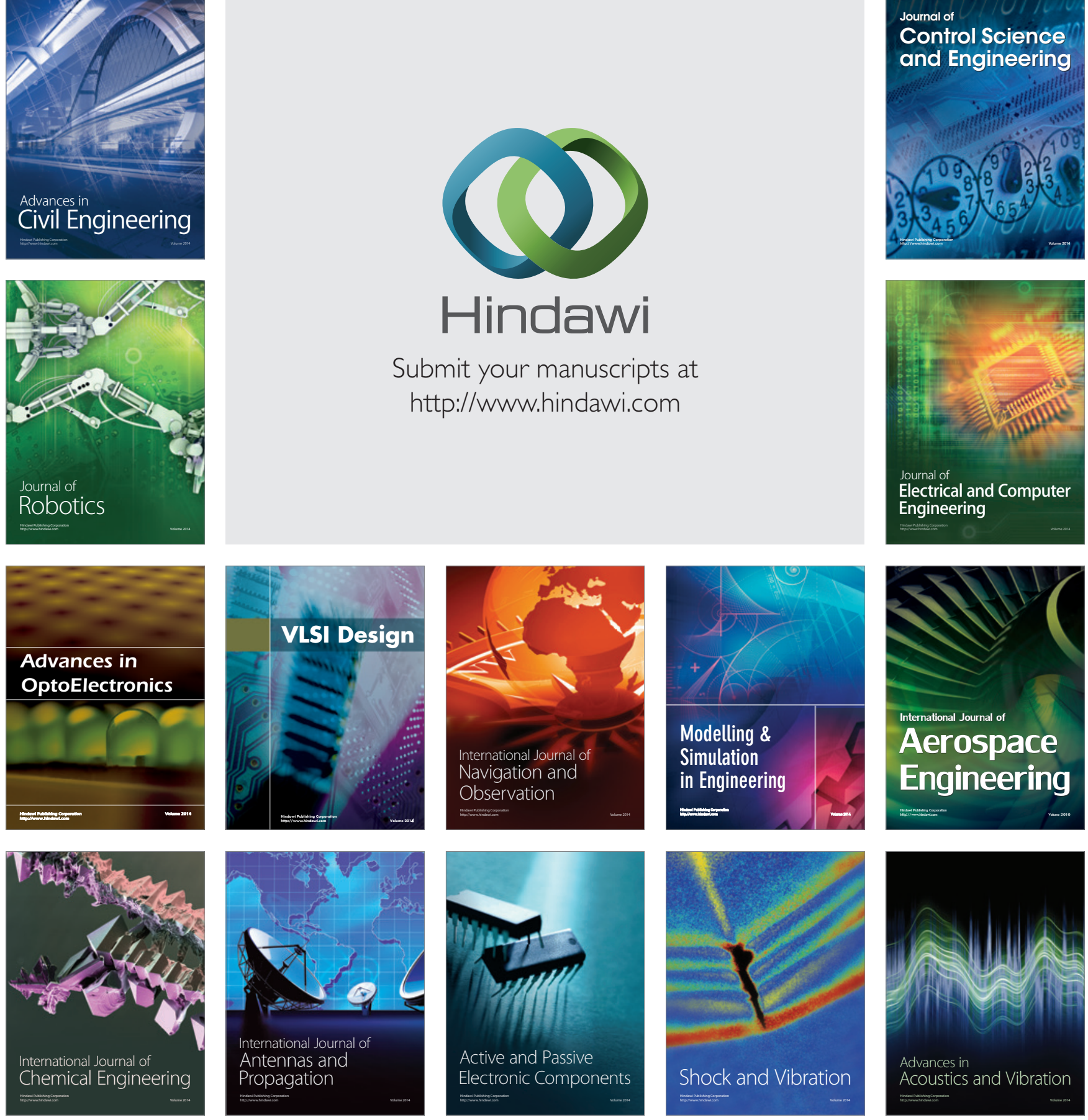